\title{
Green synthesis and characterisation of iron oxide nanoparticles using hydroponically grown spinach plant extract
}

\author{
Smital Kulkarni ${ }^{1}$ and Mansee Thakur ${ }^{2}$ \\ ${ }^{1}$ Department of Medical Biotechnology, MGM School of Biomedical Sciences, MGMIHS, Kamothe, Navi Mumbai, \\ (M.S.) India \\ ${ }^{2}$ Department of Medical Biotechnology and Central Research Laboratory, MGMCET, MGM School of Biomedical \\ Sciences, MGM Medical College Building, MGM Institute of Health Sciences, Kamothe, Navi Mumbai (M.S.) India \\ Email : mansibiotech79@gmail.com
}

Article Info : Received : 16.02.2018; Revised : 15.03.2018; Accepted : 28.03.2018

Recent advances in Nanoscience and Nanotechnology radically changed the way we diagnose, treat, and prevent various diseases in all aspects of human life. Iron oxide nanoparticles (IONPs) are one of the most vital and fascinating nanomaterial among several metallic nanoparticles that are involved in biomedical applications. IONPs have been focused on budding applications in magnetic resonance imaging, drug delivery across biological barriers or in cancer treatment by magnetic field-induced hyperthermia. In this article, we discuss the green synthesis and characterization of IONPs using hydroponically grown spinach plants leaf extract. The use of plants in the green synthesis of nanoparticles emerges as a cost-effective and eco-friendly approach. Characterization of nanoparticles was done using different methods, which include; Fourier Transform Infrared Spectroscopy (FTIR), X-ray Diffraction (XRD), Scanning Electron Microscope (SEM), Energy Dispersive Spectroscopy analysis (EDS) and Atomic Absorption Spectroscopy (AAS). Fourier transform infrared spectroscopy identifies the functional groups of active components presents on the surface of nanoparticles. The crystalline nature of the particles was validated from an X-ray diffractometer. The size and stability were detected using SEM-EDS analysis. Iron content was found to be $40.34 \%$ by AAS.

Key words : Green synthesis, IONPs, Spinach leaf extract, Hydroponic method

How to cite this paper : Kulkarni, Smital and Thakur, Mansee (2018). Green synthesis and characterisation of iron oxide nanoparticles using hydroponically grown spinach plant extract. Asian J. Bio. Sci., 13 (1) : 44-49.DOI : 10.15740/HAS/AJBS/13.1/44-49. 